\title{
Chemokines and Chemokine Receptors Critical to Host Resistance Following Genital Herpes Simplex Virus Type 2 (HSV-2) Infection
}

\author{
Manoj Thapa ${ }^{1}$ and Daniel J.J. Carr ${ }^{*}, 1,2$ \\ ${ }^{I}$ Department of Microbiology, Immunology, and ${ }^{2}$ Ophthalmology, The University of Oklahoma Health Sciences Center, \\ Oklahoma City, Oklahoma-73104, USA
}

\begin{abstract}
HSV-2 is a highly successful human pathogen with a remarkable ability to elude immune detection or counter the innate and adaptive immune response through the production of viral-encoded proteins. In response to infection, resident cells secrete soluble factors including chemokines that mobilize and guide leukocytes including T and NK cells, neutrophils, and monocytes to sites of infection. While there is built-in redundancy within the system, chemokines signal through specific membrane-bound receptors that act as antennae detailing a chemical pathway that will provide a means to locate and eliminate the viral insult. Within the central nervous system (CNS), the temporal and spatial expression of chemokines relative to leukocyte mobilization in response to HSV-2 infection has not been elucidated. This paper will review some of the chemokine/chemokine receptor candidates that appear critical to the host in viral resistance and clearance from the CNS and peripheral tissue using murine models of genital HSV-2 infection.
\end{abstract}

Keywords: Genital HSV-2, chemokines, chemokine receptors, leukocytes, CNS.

\section{HSV-2 BIOLOGY}

HSV-2 is a large $(150-200 \mathrm{~nm})$ double-stranded, DNA virus and a member of the subfamily $\alpha$-Herpesviridae $[1,2]$. A mature virus contains a core, an icosahedral capsid, a tegument in which additional viral proteins reside, and an outer envelope [1]. An approximately 150,000 base pair linear DNA is packaged inside the capsid that encodes at least 80 different viral genes [1]. The outer membrane envelope contains viral glycoproteins (e.g. $\mathrm{gB}, \mathrm{gC}, \mathrm{gD}$ and heterodimer $\mathrm{gH} / \mathrm{gL}$ ) involved in a multistep viral entry into the target cell $[3,4]$. The viral entry begins with interaction of $g B$ and $\mathrm{gC}$ to heparin sulfate proteoglycans present on the surface of target cells followed by $\mathrm{gD}$ binding to other surface receptors including herpes virus entry mediator A and nectin- $1 \alpha$ $[2,4]$. The viral envelope subsequently fuses with the target cell membrane which requires $\mathrm{gD}, \mathrm{gB}$ and the heterodimer $\mathrm{gH} / \mathrm{gL}$ [2]. Following viral entry, local replication commences with a sequential cascade of viral lytic gene transcription/translation and subsequent packaging of unit length viral DNA into empty viral capsids [5-7]. The capsid then acquires viral tegument and glycoproteins followed by the envelopment of the capsid on the underside of the nuclear membrane [6]. After successful packaging of infectious virions, the virus is released thru the rupture of the cell membrane where it will enter sensory nerve endings in the basal aspect of epithelium and via retrograde transport traffic to sacral ganglia in the CNS $[7,8]$. One of the hallmark features of HSV-2 is the establishment of latency in a subpopulation of neurons following acute infection of sensory

*Address correspondence to this author at the Department of Ophthalmology, DMEI \#415, The University of Oklahoma Health Sciences Center, 608 Stanton L Young Blvd., Oklahoma City, OK 73104, USA; Tel: 405-2718784; Fax: 405-271-8781; E-mail: dan-carr@ouhsc.edu ganglia $[9,10]$. In normal adults, it can cause recurrent infection at the original portal of entry as well as adjacent sites after reactivation [11].

\section{HSV-2 INFECTION OF THE CNS}

HSV-2 is one of the most common causes of genital ulcer disease in humans that can result in fatal encephalitis and meningitis $[8,10,12]$. Approximately forty to sixty million individuals are infected with HSV-2 in the United States only, with nearly six to eight hundred thousand clinical cases annually [13]. In the immunocompromised patient as well as newborns, the virus can elicit severe and often fatal CNS infection [14-16]. Fortunately, even though a relatively large percentage of the population is seropositive for HSV-2 only a small percentage is subjected to life-threatening complications [2]. However, the increasing prevalence of genital herpes in young adults and co-incidence of HSV-2 with HIV/AIDS are indicative of a major public health impact $[17,18]$. To underscore this point, recent evidence suggest the acquisition of HIV and other microbial pathogens increases significantly in HSV-2-infected individuals [17, 19]. Consequently, the need to identify host factors that contribute to resistance against HSV-2 infection/reactivation is tantamount toward the development of an effective prophylactic/therapeutic vaccine.

\section{IMMUNE RESPONSE TO GENITAL HSV-2 INFEC- TION IN A MOUSE MODEL}

The development of a mouse model for genital HSV-2 infection has contributed significantly to understanding the role of both innate and adaptive immune responses to infection [20, 21]. During initial infection of the genital mucosal surface, virus replicates primarily in the epithelium where the pattern recognition receptor (PRR) expressing epithelial cells or innate immune cells including dendritic cells (DCs) 
and natural killer (NK) cells recognize viral-associated structures (dsDNA CpG motifs, dsRNA, etc.) and induce the secretion of anti-viral cytokines (type I interferons, IFNs) and chemokines [10]. PRR includes germ-line encoded Toll-like receptors (TLRs) which are expressed on epithelial cells, resident DCs and NK cells [10,22]. Of the 12 TLRs found in the mouse, two endosome associated receptors TLR3 and TLR9 are involved in protection against genital HSV-2 infection [23-26]. TLR3 and TLR9 recognize viral nucleic acids i.e. dsRNA and dsDNA (CpG motifs) respectively [22]. The recognition of ligands by TLR3 induces nuclear factor-kappa $\mathrm{B}(\mathrm{NF}-\mathrm{kB})$ and interferon regulatory factor 3 (IRF3) pathways whereas TLR9 induces NF-kB through the myeloid differentiation factor (MyD88)-dependent pathway resulting in expression of interferons and pro-inflammatory cytokines [22]. The activation of DC through TLR9 has been shown to induce IFN- $\alpha$ in response to HSV-2 infection [27]. However, TLR9 is not required for chemokine expression or up-regulation in the vaginal tissue following HSV-2 infection [28]. The absence of chemokine induction by TLR9 in the genital tract was not due to a lack of local expression [24, 29]. These studies implicate a possible role of TLR3 and/or other pattern recognition receptors for local expression of chemokines in response to genital HSV-2 infection in mice.

Recent studies have identified a number of chemokine/ cytokine products in the vaginal mucosa following genital HSV-2 infection [30, 31]. The chemokine expression in the vagina influences the mobilization and activation of innate immune cells including polymorphonuclear cells (PMNs), macrophages, and NK cells which play vital role to limit initial viral replication and facilitate adaptive immune response [7, 10]. In addition to chemokines, the importance of the innate immune response including NK cells, NKT cells, and the production of type I IFN ( $\alpha / \beta$ interferon), IL- 12 , IL15 and IL-18 in suppressing HSV-2 replication and virusmediated mortality have been demonstrated using neutralizing antibodies or gene disrupted mice [32-34]. NK cells monitor HSV-2 infection operating through cytolytic processes and possibly through the production of IFN- $\gamma$ [31]. DCs are crucial for the development of an adaptive immune response to virus infection $[7,10]$. DCs encounter viral antigens at the site of infection, migrate to the draining lymph nodes and mature with upregulation of co stimulatory molecules and secretion of cytokines [7]. DCs present viral peptides to $\mathrm{T}$ lymphocytes in the context of MHC molecules and stimulate the generation of virus-specific effector $\mathrm{T}$ lymphocytes in the lymphoid organs [7, 10] that are critical in suppressing viral replication [35-38]. The role of $\mathrm{CD}^{+} \mathrm{T}$ cells includes the production of anti-viral cytokines including IFN- $\gamma$ and TNF- $\alpha$ as well as cytolytic activity mediated by perforin/granzyme and Fas/FasL pathways to limit virus replication and spread [8, 35, 37-39].

Recent data suggests HSV-2 trafficking to the CNS is greatly influenced by the innate immune response generated at the primary site of infection [30]. Specifically, the inability of CXCL10 deficient mice (CXCL10 ${ }^{-/-}$) to mobilize NK cells to vaginal tissue to the same extent as wild type (WT, $\mathrm{C} 57 \mathrm{BL} / 6$ ) animals is associated with early CNS virus entry. The outcome includes increased mortality, higher viral loads, and severe inflammation in the CNS during acute infection [30]. A schematic representation of genital HSV-2 infection in a mouse model and the ensuing immune response is summarized in Fig. (1).

\section{CHEMOKINES IN THE CNS DURING HSV-2 INFEC- TION}

Chemokines are small (8-17-kd molecular mass) secreted peptides constitutively produced or induced after viral infection [40, 41]. Currently, approximately 50 chemokines and 20 chemokine receptors have been reported [41]. Based on the first two paired and conserved cysteine molecules at the amino-terminal end, chemokines have been classified into four groups: CXC type chemokines, CC type chemokines, $\mathrm{CX}_{3} \mathrm{C}$ chemokines (one member) and $\mathrm{C}$ chemokines (two members) [40]. Similarly, chemokine receptors are G-protein coupled, seven-transmembrane receptors classified according to the chemokine(s) they bind [41]. Many chemokines are redundant in function and/or promiscuous in binding multiple receptors, but selectivity in tissue expression and targeting specific effector cells for recruitment may ultimately influence the inflammatory response of the host and overall outcome of the infection. Upon receptor binding, the Gprotein complex dissociates into two subunits $\mathrm{G} \alpha$ and $\mathrm{G} \beta \gamma$ [42]. The former subunit induces the activation of phosphatidylinositol 3-kinase (PI3-kinase) while another subunit induces phospholipase $\mathrm{C}$, protein kinase $\mathrm{C}$, and $\mathrm{Ca}^{2+}$ influx [42]. In addition, mitogen activated protein (MAP) kinase and Janus kinase/signal transducers and activators of transcription (JAK/STAT) signaling are also involved in chemokine-receptor signaling [43].

Apart from their participation in mediating chemotaxis, $\mathrm{T}$ cell differentiation, cell cycle, and angiogenesis [42], chemokines are also involved in several inflammatory events including viral infection and autoimmune disease [44]. Their critical role in genital HSV-2 infection can well be anticipated, and studies have provided evidence of chemokine and pro-inflammatory cytokine production in the CNS following infection with HSV-2 [30, 31, 45-47]. However, most of the studies have focused on the mobilization of $\mathrm{T}$ and $\mathrm{B}$ cells into the vagina or mobilization of cells between vaginal epithelium and the draining lymph nodes during infection. The expression of chemokines in the nervous system and the temporal or spatial relationship they have with lymphocyte mobilization have not been elucidated.

\section{CXCL1}

Keratinocyte-derived chemokine (KC, CXCL1) is an ELR (Glu-Leu-Arg) containing CXC type chemokine and a functional homologue of IL-8 [48, 49]. The epithelial cells of female genital mucosa are capable of producing CXCL1 in culture in response to HSV-2 infection [50]. CXCL1 expression is up-regulated in the vagina and $\mathrm{CNS}$ of mice during acute HSV-2 infection [30]. The chemokine specifically targets neutrophils through the receptor CXCR2 promoting chemotaxis and activation of neutrophils [51, 52]. Neutrophils are the early and pre-dominant innate immune cells that infiltrate the genital tract and contribute toward the resolution of HSV-2 [7, 10, 53, 54]. Currently, the induction of CXCL1 in HSV-2-infected tissue is unknown but the presence of NF-kB binding site within the CXCL1 promoter suggests the potential involvement of PRR and/or proinflammatory molecules in CXCL1 induction [55-59]. An earlier study found neither IL-6, IFN- $\gamma$, nor MAP kinase 


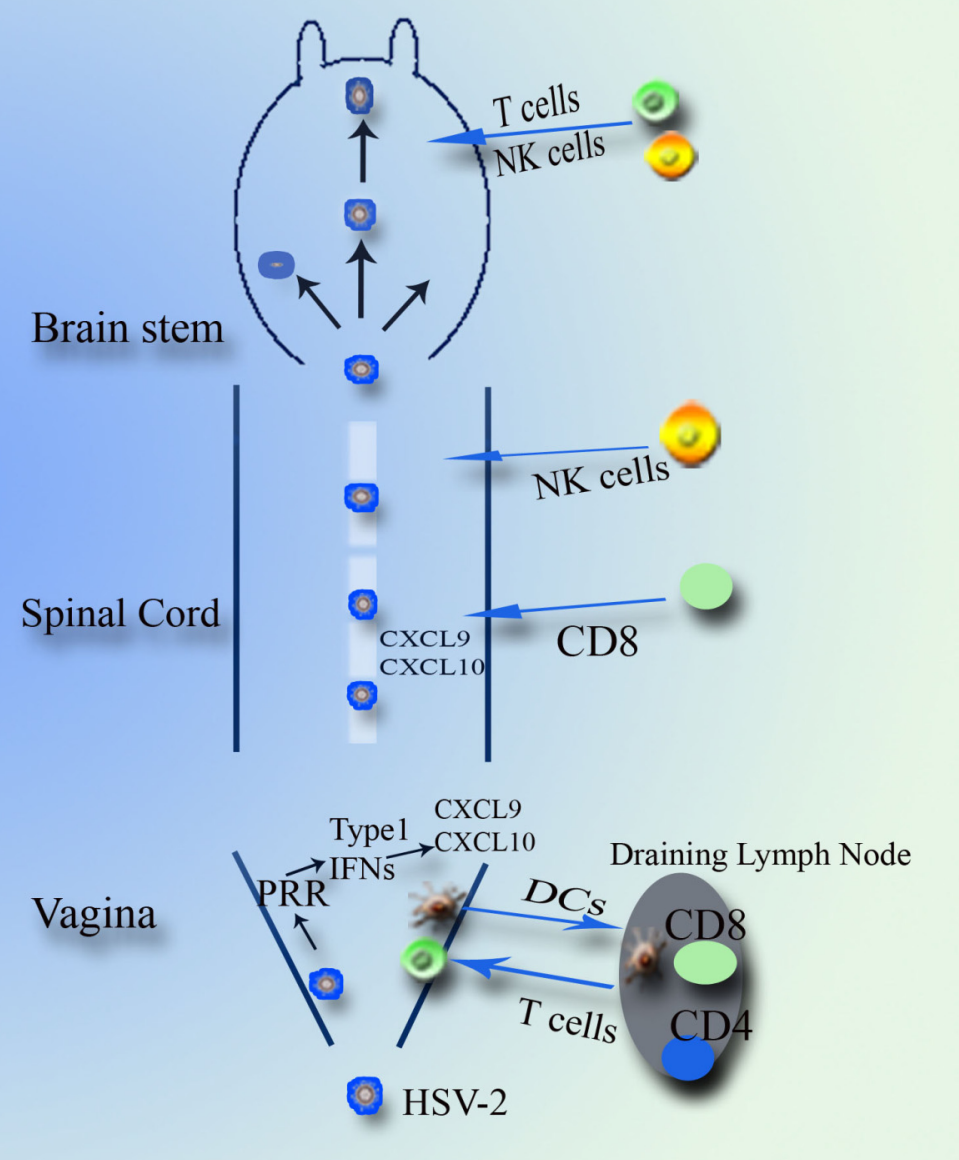

Fig. (1). A schematic representation of acute genital HSV-2 infection and the ensuing immune response in a mouse. Following inoculation, virus infects the mucosa of the vagina and local replication occurs in the epithelial cells. Recognition of virus by epithelial cells, DCs and NK cells in the vagina induces secretion of soluble factors including type 1 interferon which in turn induces the secretion of chemokines/cytokines including CXCL9 and CXCL10. Chemokines recruit PMNs, macrophages, and NK cells to the vagina. T cells are mobilized later to the site upon induction of the adaptive immune response in the organized lymphoid organs. After successful replication in the vagina, virus enters sensory nerve endings in the basal aspect of the epithelium and traffics to sacral ganglia in the CNS. Virus undergoes a second lytic replication in the sensory ganglion and further travels to the brain. The lytic replication in the CNS induces inflammatory responses with local production of chemokine/cytokine products including CXCL9, CXCL10, \& TNF- $\alpha$. The chemokine/cytokine storm mediates the infiltration of PMNs, macrophages, NK cells and effector T cells to the CNS.

pathways up-regulate CXCL1 production by astrocytes in culture in response to Theiler's murine encephalomyelitis virus (TMEV) infection [49]. However, IL-1 $\alpha$ and TNF- $\alpha$ have been found to up-regulate CXCL1 production by astrocytes [49]. TNF- $\alpha$ alone may not be responsible for CXCL1 induction within the CNS since anti-TNF- $\alpha$ antibody administered in $\mathrm{HSV}-2$ infected mice does not significantly reduce expression of CXCL1 within the spinal cord or brain stem [Thapa and Carr, manuscript submitted]. Collectively, CXCL1 expressed locally within the genitalia is likely involved in the initial immune response through the recruitment of PMNs, a potent, innate immune component to HSV2 infection.

\section{CXCL9}

Monokine induced by interferon- $\gamma$ (MIG, CXCL9) is a non-ELR containing CXC-type chemokine that specifically binds the CXCR3 receptor expressed on activated $\mathrm{T}$ cells, NK cells, monocytes, DCs, and B cells [60-64]. The strong induction of CXCL9 in the CNS in response to viral pathogens including HSV-2, lymphocytic choriomeningitis virus, murine hepatitis virus and vaccinia virus [30, 65-67] supports a central role for this chemokine participation in the CNS immune response.

CXCL9 deficient (CXCL9 ${ }^{-/-}$) mice are sensitive to HSV-2 infection compared to WT animals, but less so than $\mathrm{CXCL}_{10} 0^{-/-}$mice based on viral titer, inflammation, and mortality. Compared to CXCL10 expression, CXCL9 expression is delayed in the vagina but rapidly elevated in the draining lymph nodes (Inguinal/Iliac lymph nodes, I/ILN) following infection [30]. By comparison, CXCL10 levels gradually increase post infection but do not reach the same level achieved by CXCL9 in the draining lymph nodes [30]. Taken together, it would appear the early chemokine response is segregated based on tissue expression negating redundancy. In addition, $\mathrm{CXCL} 9^{-/-}$mice compensate for the loss of CXCL9 with CXCL10 levels similar to WT mice. Even though $\mathrm{CXCL9}^{-/-}$mice express appreciable levels of CXCL10, the loss of CXCL9 in the spinal cord results in a reduction in $\mathrm{NK}$ cell and virus-specific $\mathrm{CD}^{+} \mathrm{T}$ cell mobilization and cytolytic activity along with an elevation in viral 
titer and expression of select chemokines including CXCL1, CCL2, CCL3 and CCL5 [30]. The expression of these chemokines in the CNS is consistent with other virus infections including vesicular stomatitis virus, lymphocytic choriomeningitis, and mouse hepatitis virus [68-70]. Collectively, the outcome of a deficiency in CXCL9 expression is to some degree compensated by the expression of CXCL10 which preserves the recruitment capabilities for NK cells. However, $\mathrm{CD}^{+}$effector $\mathrm{T}$ cells mobilization to the $\mathrm{CNS}$ is attenuated and associated with an elevation of virus replication and spread. In addition to effector cell trafficking to the $\mathrm{CNS}$, other factors are likely involved in viral surveillance (e.g., type I interferons) within the spinal cord and brain requiring further analysis.

\section{CXCL10}

Interferon inducible protein-10 (IP-10, CXCL10) is another non-ELR containing CXC type chemokine that specifically binds the CXCR3 receptor expressed on activated $\mathrm{T}$ cells and facilitates the recruitment of virus-specific $\mathrm{T}$ cells into the CNS promoting a Th1 response [60, 62, 71, 72]. Similar to CXCL9, the strong induction of CXCL10 in the $\mathrm{CNS}$ in response to many viral pathogens including HSV-2, murine hepatitis virus, murine CMV, dengue virus, and HIV as well as Toxoplasma gondii [30, 73-77] underscores the importance of this chemokine in the local immune response.

In a recent report, it was found even though both CXCL9 and CXCL10 operate through the same receptor, CXCR3, CXCL10 deficient (CXCL10 ${ }^{-/-}$) mice are more susceptible to infection compared to CXCL9 ${ }^{-/-}$or WT mice based on viral titer, mortality and clinical presentation following HSV-2 infection (Fig. 2a-c) [30]. The increase in susceptibility may, in part, be due to a failure to fully compensate for the loss of CXCL10 with CXCL9 levels. This relationship correlates with a reduction in NK cell mobilization to the vagina and early detection of HSV-2 in the spinal cord of CXCL10 ${ }^{-/-}$ mice [30].

The uncontrolled expression of chemokines and other soluble inflammatory factors promotes excessive infiltration of inflammatory leukocytes into the CNS adversely affecting the host ultimately resulting in exaggerated immunopathology $[30,63]$. A case in point, TNF- $\alpha$ is the sole cytokine found to be elevated in the nervous system of HSV-2- infected CXCL10 $0^{-/}$mice [30]. As TNF- $\alpha$ is neurotoxic [78], it is predicted the increase in CNS TNF- $\alpha$ levels in these mice may be the primary contributing factor in the higher mortality rate in comparison to $\mathrm{WT}$ or $\mathrm{CXCL}^{-/-}$mice. In fact, a recent study found neutralization of TNF- $\alpha$ in HSV-2infected CXCL10 ${ }^{-/-}$mice offset the elevated mortality rate of these mice despite increased CNS viral titers [Thapa and Carr, manuscript submitted].

\section{CCL2}

Monocyte chemoattractant protein-1 (MCP-1, CCL2) is a $\mathrm{C}-\mathrm{C}$ type chemokine often found associated with inflammatory CNS disorders, lung infections, and viral infections including HSV-2 [30, 79-81]. Using in situ hybridization techniques, CCL2 was found to be induced rapidly in the infected brain of mice in a restricted fashion both by endothelial and parenchymal microglial cells as well as by infiltrating cells [47]. CCL2 can attract macrophages, monocytes and $\mathrm{T}$ cells that express the CCR2 receptor [82]. The association of CCL2 and CCR2 in neuropathogenesis has also been demonstrated in other disease models including experimental autoimmune encephalomyelitis (EAE) [83]. In addition, resistance of CCR2 deficient mice to EAE [83] correlates with impairment of macrophage recruitment to the CNS and provides support for this chemokine/receptor system as a critical component in the development of CNS inflammatory processes. Previous studies have found CCL2 expression is regulated by NF-kB as NF-kB binding sites are located $2700 \mathrm{bp}$ upstream of the transcriptional start site for CCL2 $[84,85]$. In addition, TNF- $\alpha$ induces CCL2 transcription in vitro as well as in vivo [86-88]. A recent study found neutralization of TNF- $\alpha$ reduces the expression of CCL2 in the CNS of HSV-2-infected CXCL10 $0^{-/-}$mice following genital infection with HSV-2 [Thapa and Carr, manuscript submitted]. This observation suggests the expression of CCL2 in CNS of HSV-2-infected mice may be TNF- $\alpha$ regulated most probably through an NF-kB-dependent pathway.

\section{CCL3}

Macrophage inflammatory protein- $1 \alpha$ (MIP-1 $\alpha$, CCL3) is another $\mathrm{C}-\mathrm{C}$ type chemokine mainly produced by macrophages, DCs, neutrophils, astrocytes, and fibroblasts [43, 89, 90]. The chemokine signals primarily through CCR 1 and CCR5 expressed by monocytes, T cells, NK cells, neutro- (a)

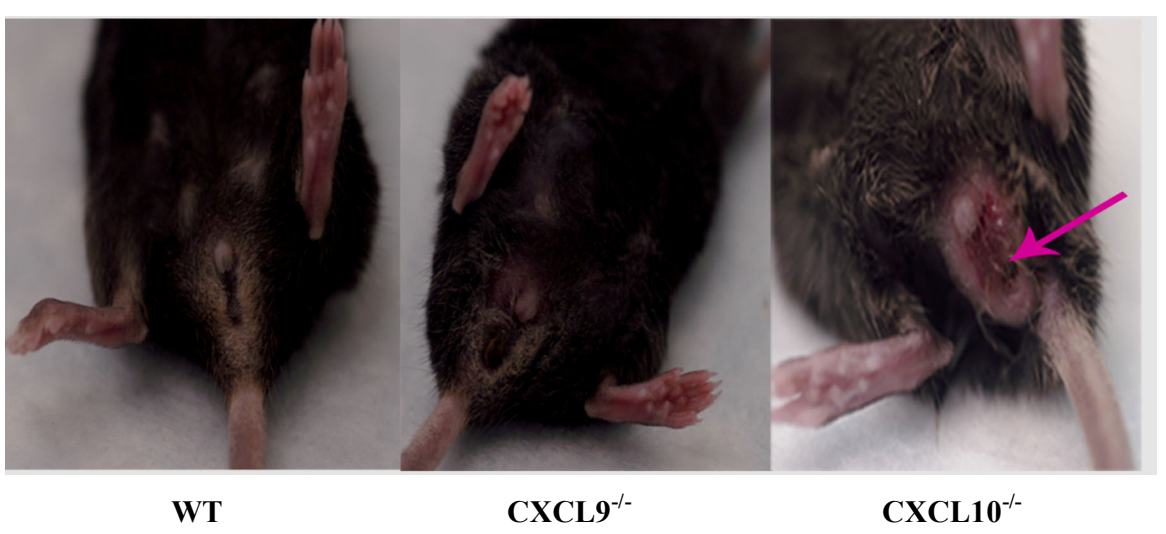

Fig. (2). Overt genital lesions in HSV-2-infected CXCL10 $10^{-/}$mice. WT (C57BL/6), CXCL9 ${ }^{-/-}$and CXCL10 ${ }^{-/-}$mice were infected with HSV-2 (2,000 PFU/vagina) and assessed for outward signs of inflammation on day 7 post infection. Arrow indicates peri-genital lesions. 
phils and DCs [91, 92]. During HSV-2 infection, CCL3 is elevated in the infected tissue of mice [30]. The induction of CCL3 has been ascribed to regulation by NF-kB dependent pathways rather than interferon regulatory factors since there is no ISRE element in the CCL3 promoter [41, 93, 94]. In addition to NF-kB, the presence of a CD28RE element in close proximity to an AP-1 site suggests additional regulatory factors may be activated following virus infection [41]. There is evidence CCL3 drives Th1 development through IFN- $\gamma$ production [95]. To this end, the application of CCL3 cDNA in a DNA vaccine induces antigen-specific Th1 type cell-mediated responses through production of IFN- $\gamma$ and IL2 which protects vaccinated animals against HSV-2 infection [95]. In addition, CCL3 has been shown to possess anti-HIV1 activity by binding to co-receptors of the virus [44]. However, CCL3 has also been linked to immunopathology associated with viral and bacterial infections as well as EAE due to its major role in the recruitment of mononuclear cells [96, 97]. These data suggest a dichotomy in CCL3 function depending on the model under study. As TNF- $\alpha$ has been described as one of the inducing factors for CCL3 [58], the elevated CCL3 levels in CNS of chemokine/receptor deficient mice $\left(\mathrm{CXCL}^{-/-}, \mathrm{CXCL} 10^{-/-}, \mathrm{CCR}^{-/-}\right.$) mice following genital HSV-2 infection might be TNF- $\alpha$-mediated $[30,31]$.

\section{CCL5}

Regulated upon activation, normal $\mathrm{T}$ cell expressed and secreted (RANTES, CCL5) signals through four different receptors CCR1, CCR3, CCR4 and CCR5 which are expressed by $\mathrm{T}$ cells, NK cells, monocytes, basophils and memory T cells [98-100]. Previous studies suggest NF-kB, MAP kinase and IRF3 are involved in regulating CCL5 expression during viral infection [101-104]. Relative to HSV-2, expression of CCL5 by macrophage is regulated by both NF$\mathrm{kB}$ and IRF3 [104]. An NF-kB binding site resides in the CCL5 promoter at -30 position relative to the transcriptional start site [105]. It has also been reported that TNF- $\alpha$ enhances CCL5 expression through an NF-kB- dependent pathway [106]. In comparing mice vaccinated with constructs containing CCL2, CCL3 or CCL5 along with HSV-2 gD DNA, one study reported the CCL5 transgene possessed greater efficacy compared to CCL2 or CCL3 in response to HSV-2 infection as measured by reduced morbidity and mortality [100]. CCL5 supported the recruitment of memory $\mathrm{CD}^{+}{ }^{+} \mathrm{T}$ cells as well as Th1 differentiation [100]. Following genital HSV-2 infection, CCL5 expression significantly increases in vaginal tissue as well as the spinal cord and brain stem [30]. The absence of CCL5 has not been addressed in the genital HSV-2 mouse model. However, the application of anti-CCL5 antibody to mouse hepatitis virus-infected mice suggests CCL5 expression promotes inflammation and has an overall detrimental impact on CNS infection [107].

\section{CXCR3}

CXCR3 is a G-protein coupled receptor specific for CXC-type chemokines CXCL9, CXCL10 and CXCL11 [62, 108, 109]. CXCR3 is preferentially expressed on activated T cells, NK cells and macrophages [109, 110]. Previous findings suggest the expression of both CXCR3 ligands CXCL9 and CXCL10 are required to mobilize virus-specific $\mathrm{CD} 8^{+} \mathrm{T}$ cells to the CNS as well as generate an effective immune response to genital HSV-2 infection [30]. Moreover, studies have implicated the importance of CXCR3 expression on plasmacytoid dendritic cell (pDC) migration and CTL function within the lymph node [111]. These observations suggest CXCR3 signaling may be critical for the generation of CTL effector function in lymph nodes and as a consequence, play an important role in controlling HSV-2 infection.

The importance of CXCR3 signaling in the recruitment of $\mathrm{T}$ cells has been demonstrated in neuro-inflammatory diseases such as multiple sclerosis, EAE, and viral infections of the CNS $[110,112,113]$. We are currently investigating the role of CXCR3 in the host response to genital HSV-2 infection. Preliminary studies with CXCR3 deficient $\left(\mathrm{CXCR}^{-/-}\right)$ mice suggest they are highly sensitive to HSV-2 infection compared to WT controls as determined by HSV-2 titers and mortality [Thapa and Carr, unpublished result]. In contrast to reduced mobilization of effector cells which are observed in the absence of CXCL9 and CXCL10 expression, HSV-2infected $\mathrm{CXCR}^{-/-}$mice mobilize $\mathrm{HSV}$-specific $\mathrm{CD}^{+} \mathrm{T}$ cells to infected tissue normally but are found to have a defect at the level of CTL effector function. It is anticipated, CXCR3 expression is required for appropriate activation (education) of effector cells rather than recruitment/mobilization in the genital HSV-2 mouse model.

\section{CCR5}

CCR5 is a chemokine receptor mainly expressed on $\mathrm{T}$ cells, NK cells, macrophages and DCs and interacts with its ligands CCL3, CCL4 and CCL5 [114-116]. Previously, it was reported the absence of CCR5 had no significant impact on $\mathrm{T}$ cell mobilization [31]. However, NK cell infiltration was diminished and a reduction in NK cell levels was associated with a rise in tissue-associated HSV-2 titers [31]. Similarly, the role of CCR5 has been implicated in resistance to intraperitoneal infection with HSV-2 impacting on NK cell recruitment and activity at the site of infection [114]. Likewise, the significance of CCR5 mobilization of NK cells in response to an unrelated pathogen, Toxoplasma gondii has also been described [116]. Our results are in agreement with observations reporting no difference in $\mathrm{T}$ cell trafficking to the CNS following an intracranial infection with lymphocytic choriomeningitis virus [117] or the role of CCR5 on NK cell recruitment to the CNS following Toxoplasma gondii infection [116]. Taken together, CCR5 appears to be a necessary receptor within the nervous system to control genital HSV-2 infection in mice primarily through NK cell trafficking.

\section{EFFECTOR CELLS FROM LYMPH NODE VS SPLEEN: WHICH IS MORE PROTECTIVE?}

Lymph nodes and spleen are organized secondary lymphoid organs critical to the development of the adaptive immune response [118]. Both lymph nodes and spleen trap antigen and antigen presenting cells from sites of infection and provide a advantageous microenvironment to present antigens to circulating lymphocytes [118]. Lymphocytes are known to migrate to draining lymph nodes through lymphatic vessels [119], and chemokines are found to attract lymphocytes from the blood as they enter lymph nodes through high endothelial venules [120]. However, the spleen has no direct association with the lymphatic system and collects antigens from blood [118]. An earlier study indicated 
Table 1. Chemokines and Chemokine Receptors Critical to Genital HSV-2 Infection

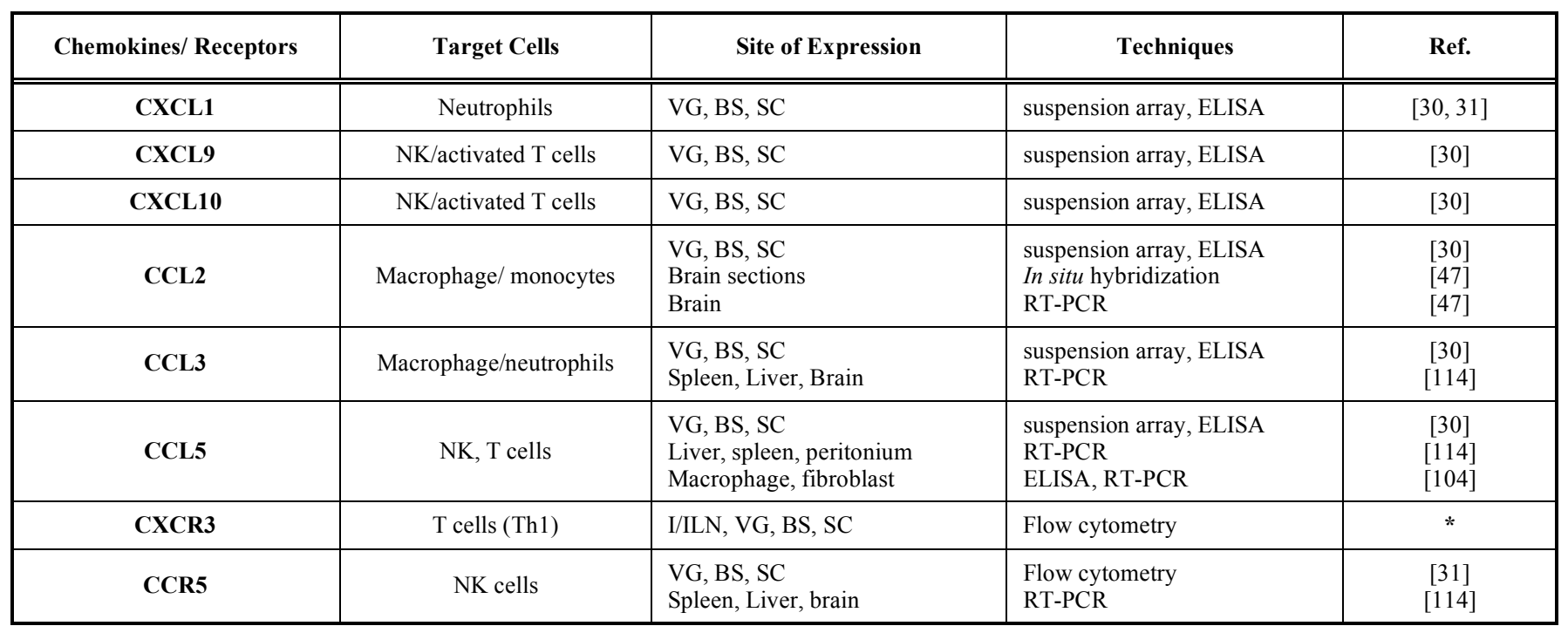

HSV-2, Herpes simplex virus Type 2; VG, vaginal tissue; BS, brain stem; SC, spinal cord; I/ILN, Inguinal/Iliac lymph node; RT-PCR, reverse transcriptase polymerase chain reaction; *, unpublished data.

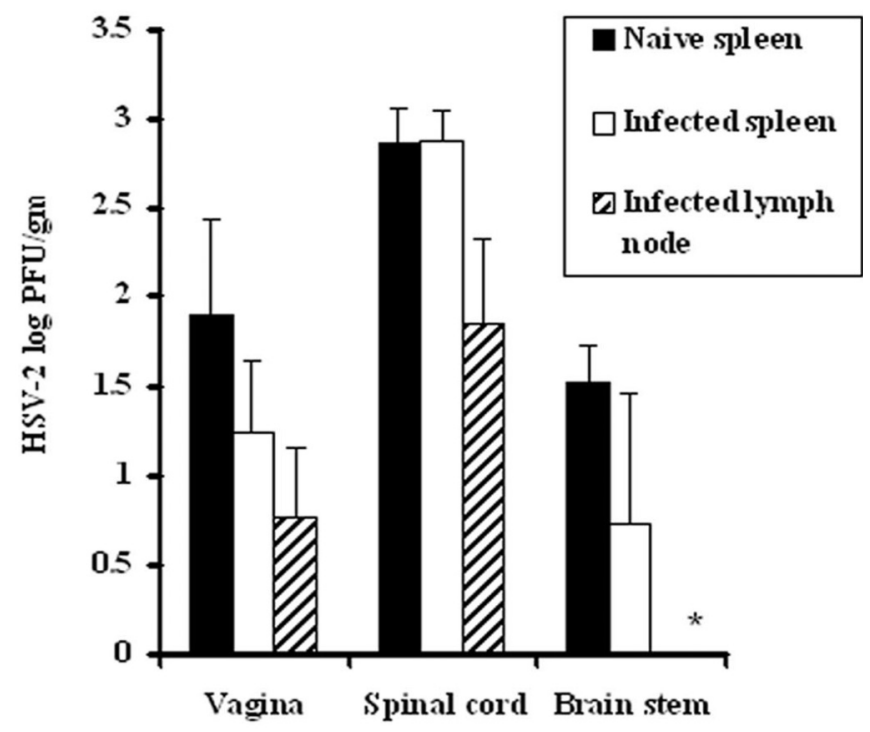

Fig. (3). Effector cells from lymph nodes suppress HSV-2 spread in vivo. WT $(\mathrm{C} 57 \mathrm{BL} / 6)$ mice $(\mathrm{n}=3)$ were infected with HSV-2 $(2,000$ PFU/vagina) and exsanguinated on day 7 p.i., and lymph nodes \& spleen were removed and processed. One million cells $\left(1 \times 10^{\wedge} 6\right)$ from lymph nodes and spleen were introduced intravenously to naive WT mice ( $n=6 /$ group) that were then infected with HSV-2 (2000 PFU/vagina). Recipients of spleen cells from naive mice served as controls. Mice were exsanguinated on day 7 p.i. and vaginal tissue, spinal cord, and brain stem were removed, processed and assayed for HSV-2 content by standard plaque assay. The viral titer is expressed as mean log PFU+/- SEM. *, p $<0.05$ comparing three different HSV-2-infected groups as determined by ANOVA \& Tukey's post hoc $T$-test.

$\mathrm{CD} 1 \mathrm{~b}^{+}$sub-mucosal dendritic cells present viral antigens to $\mathrm{T}$ cells in the draining lymph nodes as early as $48 \mathrm{~h}$ following infection with HSV-2 [121]. Antigen-specific T cells were found to produce IFN- $\gamma$ in an HSV-2-specific manner which was detectable in the draining lymph nodes prior to $\mathrm{T}$ cells from the spleen. We interpret the results to suggest the initial adaptive immune response takes place in the draining lymph nodes. Furthermore, it led us to speculate the magnitude of protection may differ comparing lymph node versus spleen cells after HSV-2 insult. To address this hypothesis, HSV-2-activated lymph node cells (I/ILN) or spleen cells were administered to naive mice intravenously and mice were then challenged with HSV-2. The recipients of the I/ILN cells were found to harbor significantly less infectious virus in the brain stem by day 7 p.i. compared to naive controls (Fig. 3). Likewise, viral titers were also reduced in the spinal cord of I/ILN treated mice but it did not reach significance $(p=0.05)$. By comparison, the virus titer recovered from recipients of activated spleen cells were found to be modestly but insignificantly lower than naive control (Fig. 3). Taken together, effector cells from lymph node seem to be more protective compared to spleen cells following HSV2 infection. While the results are not conclusive, they do suggest effector cells from the draining lymph nodes can antagonize HSV-2 replication and spread into the CNS following vaginal challenge.

\section{PERSPECTIVE}

Chemokines are a group of soluble peptides critical in the orchestration of the immune response to genital HSV-2 infection. Our studies implicate CXCR3 ligands, CXCL9 and CXCL10, as the first line of defense evident by their rapid and tissue-specific expression early following HSV-2 infection. CXCL9 and CXCL10 have specific roles in recruiting NK cells and virus-specific $\mathrm{T}$ cells into the primary site of infection and CNS as well as facilitate the generation of effector $\mathrm{T}$ cells in the organized lymphoid tissue. The relevance of these ligands has also been demonstrated in CXCR3 deficient mice. However, preliminary data suggest CXCR3 expression is required for appropriate activation/education of effector cells rather than recruitment [unpublished data]. Though there is redundancy within the system, individual expression of chemokine or chemokine receptors seems to be required to maximize the host immune response especially as it relates to effector cell mobilization or function. By resolving the temporal and tissue-specific 
expression of chemokines as well as the downstream effector pathways impacted by their expression, a greater understanding in the efficacious and detrimental role of chemokines in the host response to specific disease states will be appreciated. It is anticipated out of this analysis appropriate therapeutic strategies will be developed and applied to fundamental problems inherent within genital herpes infection. The contrast between atypical presentation of genital herpes infection relative to shedding incidence of virus and the local immune response including the production of chemokines within vaginal tissue is beneficial for the genesis of such therapeutic strategies against human HSV-2 infection.

\section{ACKNOWLEDGEMENTS}

The authors acknowledge Dr. Josh Farber, Dr. Andrew Luster and Dr. William A. Kuziel for the CXCL9 ${ }^{-/}$, $\mathrm{CXCL}_{10} 0^{-/-}$and $\mathrm{CCR}^{-/-}$mice respectively. All procedures were approved by the University of Oklahoma Health Sciences Center and Dean A. McGee Eye Institute animal care and use committee. This work was supported by NIH grant AI067309.

\section{REFERENCES}

[1] Taylor TJ, Brockman MA, McNamee EE, Knipe DM. Herpes simplex virus. Front Biosci 2002; 752-764.

[2] Carr DJJ, Tomanek L. Herpes simplex virus and the chemokines that mediate the inflammation. CTMI 2006; 303: 47-65.

[3] Mossman KL, Macgregor F, Rozmus J, Goryachev B, Edwards M, Smiley R. Herpes virus triggers and then disarms a host antiviral response. J Virol 2001; 75: 750-758.

[4] Koelle DM, Corey L. Recent progress in herpes simplex virus immunobiology and vaccine research. Clin Microbiol Rev 2003; 16: 96-113.

[5] King NJC, Parr EL, Parr MB. Migration of lymphoid cells from vaginal epithelium to iliac lymph nodes in relation to vaginal infection by herpes simplex virus type 2 . J Immunol 1998; 160: 11731180 .

[6] Ohara PT, Chin SM, Lavail HJ. The spread of herpes simplex virus type 1 from trigeminal neurons to the murine cornea: an immunoelectron microscopy study. J Virol 2000; 74: 4776-4786.

[7] Duerst RJ, Morrison LA. Innate immunity to herpes simplex virus type 2. Viral Immunol 2003; 16: 475-490.

[8] Harandi AM, Svennerholm B, Holmgren J, Eriksson K. Differential roles of B cells and IFN- $\gamma$-secreting $\mathrm{CD}^{+} \mathrm{T}$ cells in innate and adaptive immune control of genital herpes simplex virus type 2 infection in mice. J Gen Virol 2001; 82: 845-853.

[9] Inagaki K, Daikoku T, Goshima F, Nashiyama Y. Impaired induction of protective immunity by highly virulent herpes simplex type 2 in a murine model of genital herpes. Arch Virol 2000; 145: 19892002.

[10] MasCasullo V, Fam E, Keller MJ, Herold BC. Role of mucosal immunity preventing genital herpes infection. Viral Immunol 2005; 18: 595-606.

[11] Singh R, Kumar A, Creery WD, Ruben M, Giulivi A, Diaz-Mitoma F. Dysregulated expression of IFN- $\gamma$ and IL-10 and impaired IFN$\gamma$-mediated responses at different disease stages in patients with genital herpes simplex virus-2 infection. Clin Exp Immunol 2003; 133: 97-107.

[12] Whitley RJ, Miller RL. Immunologic approach to Herpes Simplex Virus. Viral Immunol 2001; 14(2): 111-118.

[13] WHO [http: //www.who.int/en/]. Initiative for vaccine research. Sexually Transmitted Disease. Herpes simplex type 2 [cited 2008 March 15]. Available from www.who.int/vaccine_research/diseases/soa std/en/index3.html

[14] Parr MB, Parr LE. Mucosal immunity to herpes simplex virus type 2 infection in the mouse vagina is impaired by in vivo depletion of T lymphocytes. J Virol 1998; 72: 2677-2685.

[15] Kesson AM. Management of neonatal herpes simplex virus infection. Paediatr Drugs 2001; 3(2): 81-90.

[16] Kimberlin D. Herpes simplex virus, meningitis and encephalitis in neonates. Herpes 2004; 11(2): 65A-76A.
[17] Celum CL. The interaction between herpes simplex virus and human immunodeficiency virus. Herpes 2004; 11 (1): 36A-45A.

[18] Strick LB, Wald A, Celum C. Management of Herpes Simplex Virus Type 2 infection HIV Type 1- infected persons. Clin Infect Dis 2006; 43: 347-356.

[19] Nagot N, Ouedraogo A, Defer MC, Vallo R, Mayaud P, Perre VP. Association between bacterial vaginosis and herpes simplex virus type 2 infection: implications for HIV acquisition studies. Sex Transm Infect 2007; 83 (5): 365-368.

[20] McDermott MR, Goldsmith CH, Rosenthal KL, Brais LJ. T lymphocytes in genital lymph nodes protect mice from intravaginal infection with herpes simplex virus type 2. J Inf Dis 1989; 159: 460466.

[21] Parr MB, Kepple L, McDermott MR, Drew MD, Bozzola JJ, Parr EL. A mouse model for studies of mucosal immunity to vaginal infection by herpes simplex virus type 2. Lab Invest 1994; 70: 369380 .

[22] Uematsu S, Akira S. Toll-like receptors and Type 1 interferons. J Biol Chem 2007; 282: 15319-15323.

[23] Gill N, Deacon PM, Lichty B, Mossman KL, Ashkar AA. Induction of innate immunity against herpes simplex virus type 2 infection via local delivery of toll-like receptor ligands correlates with beta interferon production. J Virol 2006; 80 (20): 9943-9950.

[24] Ashkar AA, Bauer S, Mitchell WJ, Vieira J, Rosenthal KL. Local delivery of $\mathrm{CpG}$ oligodeoxynucleotides induces rapid changes in the genital mucosa and inhibits replication, but not entry, of herpes simplex virus type 2. J Virol 2003; 77: 8948-8956.

[25] Ashkar AA, Yao XD, Gill N, Sajic D, Patrick AJ, Rosenthal KL. Toll-like receptor (TLR)-3 but not TLR4, agonist protects against genital herpes infection in the absence of inflammation seen with CpG DNA. J Infect Dis 2004; 190: 1841-1849.

[26] Sajic D, Ashkar AA, Patrick AJ, et al. Parameters of CpG oligooxynucleotide-induced protection against intravaginal HSV-2 challenge. J Med Virol 2003; 71: 561-568.

[27] Lund J, Sato A, Akira S, Medzhitov R, Iwasaki A. Toll-like receptor 9-mediated recognition of herpes simplex virus-2 by plasmacytoid dendritic cells. J Exp Med 2003; 198: 513-520.

[28] Wuest T, Austin BA, Uematsu S, Thapa M, Akira S, Carr DJJ Intact TLR9 and type I interferon signaling pathways are required to augment HSV-1 induced corneal CXCL9 and CXCL10. J Neuroimmunol 2006; 179: 46-52.

[29] McCluskie MJ, Cartier JL, Patrick AJ, et al. Treatment of intravaginal HSV-2 infection in mice: a comparison of $\mathrm{CpG}$ oligodoxynucleotide and resiquimod (R-848). Antiviral Res 2006; 69: 77-85.

[30] Thapa M, Welner RS, Pelayo R, Carr DJJ. CXCL9 and CXCL10 expression are critical for control of genital herpes simplex virus type 2 infection through mobilization of HSV-specific CTL and NK cells to the Nervous system.. J Immunol 2008; 1098-1106.

[31] Thapa M, Kuziel WA, Carr DJJ. Susceptibility of CCR5 deficient mice is linked to NK cell mobilization. J Virol 2007; 81: 37043713.

[32] Harandi AM, Svennerholm B, Holmgreen J, Eriksson K. Interluekin-12 (IL-12) and IL-18 are important in innate defense against genital herpes simplex virus type 2 infection in mice but are not required for the development of acquired Gamma-interferonmediated protective immunity. J Virol 2001, 75 (14): 6705-6709.

[33] Svensson A, Bellner L, Magnusson M, Eriksson K. Role of IFNalpha/beta signaling in the prevention of genital herpes virus type 2 infection. J Reprod Immunol 2007; 74: 114-123.

[34] Ashkar AA, Rosenthal KL. Interleukin-15 and natural killer and NK T cells play a critical role in innate protection against genital herpes simplex virus type 2 infection. J Virol 2003; 77: 1016810171 .

[35] Milligan GN, Bernstein DI, Bourne N. T lymphocytes are required for protection of vaginal mucosae and sensory ganaglia of immune mice against reinfection with herpes simplex virus type 2 . J Immunol 1998; 160 (12): 6093-100.

[36] Koelle DM, Posavad CM, Barnum GR, Johnson ML, Frank JM, Corey L. Clearance of HSV-2 from recurrent genital lesions correlates with infiltration of HSV-specific cytotoxic T lymphocytes. J Clin Investig 1998; 101: 1500-1508.

[37] Milligan GN, Dudley-McClain KL, Young CG, Chu CF. T-cellmediated mechanisms involved in resolution of genital herpes simplex virus type 2 (HSV-2) infection of mice. J Reprod Immunol 2004; 61 (2): 115-127. 
[38] Dobbs ME, Strasser JE, Chu C, Chalk C, Milligan GN. Clearance of herpes simplex type 2 by CD $8+T$ cells requires gamma interferon and either perforin-or Fas-mediated cytolytic mechanisms. J Virol 2005; 79 (23): 14546-14554.

[39] Parr MB, Parr EL. The role of $\gamma$ interferon in immune resistance to vaginal infection by herpes simplex virus type 2 in mice. Virology 1999; 258: 282-294.

[40] Murdoch C, Finn A. Chemokine receptors and their role in inflammation and infectious diseases. Blood 2000; 95 (10): 3032-3043.

[41] Melchjorsen J, Sorensen LN, Paludan SR. Expression and function of chemokines during viral infections: from molecular mechanisms to in vivo function. J Leukoc Biol 2003; 74: 331-343.

[42] Banisor I, Leist TP, Kalman B. Involvement of $\beta$-chemokines in the development of inflammatory demyelination. J Neuroinflamm 2005; $2: 7$.

[43] Mauer M, von Stebut E. Macrophage inflammatory protein-1. Int J Biochem Cell Biol 2004; 36: 1882-1886.

[44] Ansari AW, Heiken H, Moenkemeyera M, Schmidt RE. Dichotomous effects of C-C chemokines in HIV-1 pathogenesis. Immunol Lett 2007; 110: 1-5.

[45] Lewandowski G, Hobbs MV, Bloom FE. Alteration of intracerebral cytokine production in mice infected with herpes simplex virus types 1 and 2. J Neuroimmunol 1994; 55: 23-34.

[46] Lewandowski G, Hobbs MV. Evidence for deficiencies in intracerebral cytokine production, adhesion molecule induction, and $\mathrm{T}$ cell recruitment in herpes simplex virus type 2 -infected mice. $J$ Neuroimmunol 1998; 81 (1-2): 58-65.

[47] Boivin G, Coulombe Z, Rivest S. Intranasal herpes simplex virus type 2 inoculation causes a profound thymidine kinase dependent cerebral inflammatory response in the mouse hindbrain. Eur J Neuroimmunol 2002; 16 (1): 29-43.

[48] Schall TJ. The cytokine handbook, 2nd ed., New York: In: Thomsen A. (ed.), Academic press; 1994.

[49] Rubio N, Sanz-Rodriguez F. Induction of the CXCL1 (KC) chemokine in mouse astrocytes by infection with the murine encephalomyelitis virus of Theiler. Virology 2007; 358: 98-108.

[50] Fernandez S, Gillgrass A, Kaushik C. Differential responses of murine vaginal and uterine epithelial cells prior to and following herpes simplex virus type 2 (HSV-2) infection. Am J Reprod Immunol 2007; 57 (5): 367-377.

[51] Rollins BJ. Chemokines. Blood 1997; 90: 909-928.

[52] Chensue SW. Molecular machinations: chemokine signals in hostpathogen interactions. Clin Microbiol Rev 2001; 14: 821-835.

[53] Milligan GN. Neutrophils aid in protection of the vaginal mucosae of immune mice against challenge with herpes simplex virus type 2. J Virol 1999; 73: 6380-6386.

[54] Milligan GN, Bourne N, Dudley KL. Role of polymorphonuclear leukocytes in resolution of HSV-2 infection of the mouse vagina. $\mathrm{J}$ Reprod Immunol 2001; 49: 49-65.

[55] Feng G, Ohmori Y, Chang PL. Production of chemokine CXCL1/KC by okadaic acid through the nuclear factor-kappa B pathway. Carcinogenesis 2006; 27: 43-52.

[56] Zhai Q, Luo Y, Zhang Y, et al. Low nuclear levels of nuclear factor-kappa B are essential for KC self-induction in astrocytes: requirements for shuttling and phosphorylation. Glia 2004; 48: $327-$ 336 .

[57] Mizgerd JP, Lupa MM, Spieker MS. NF-kappaB p50 facilitates neutrophil accumulation during LPS-induced pulmonary inflammation. BMC Immunol 2004; 5: 10.

[58] Ciesielski CJ, Andreakos E, Foxwell BMJ, Feldman M. TNF-2induced macrophage chemokine secretion is more dependent on NF-kB expression than lipopolysaccharides-induced macrophage chemokine secretion. Eur J Neuroimmunol 2002; 32: 2037-2045.

[59] Wood LD, Richmond A. Constitutive and cytokine-induced expression of the melanoma growth stimulatory activity/GRO alpha gene requires both NF-kappaB and novel constitutive factors. J Biol Chem 1995; 270: 30619-30626.

[60] Farber JM. Mig and IP-10: CXC chemokines that target lymphocytes. J Leukoc Biol 1997; 61: 246-257.

[61] Ghersa P, Gelati M, Colinge J, Feger G, Power C. MIG-differential gene expression in mouse brain endothelial cells. Neuroreport 2002; 13: 9-14.

[62] Liu L, Callahan MK, Huang D, Ransohoff RM: chemokine receptor CXCR3: an unexpected enigma. Curr Top Dev Biol 2005; 68: $149-181$.
[63] Whiting D, Hsieh G, Yun JJ, et al. Chemokine monokine induced by IFN- $\gamma / \mathrm{CXC}$ chemokine ligand 9 stimulates $\mathrm{T}$ lymphocyte proliferation and effector cytokine production. J Immunol 2004; 172 : 7417-7424.

[64] Park MK, Amichay D, Love P, et al. The CXC chemokine murine monokine induced by IFN- $\gamma$ (CXC chemokine ligand 9) is made by APCS, targets lymphocytes including activated B cells, and supports antibody responses to a bacterial pathogen in vivo. J Immunol 2002; 169: 1433-1443.

[65] Mahalingam S, Farber JM, Karupiah G. The interferon-inducible chemokines MuMig and Crg-2 exhibit antiviral activity in vivo. J Virol 1999; 73: 147.

[66] Liu MT, Armstrong D, Hamilton TA, Lane TE. Expression of Mig (monokine induced by interferon- $\gamma$ ) is important in T lymphocyte recruitment and host defense following viral infection of central nervous system. J Immunol 2001; 166: 1790-1795.

[67] Christensen JE, Nansen A, Moos T et al. Efficient T-cell surveillance of the $\mathrm{CNS}$ requires expression of the $\mathrm{CXC}$ chemokine receptor 3. J Neurosci 2004; 4849-4858

[68] Asensio VC, Campbell IL. Chemokine gene expression in brains of mice with lymphocytic choriomeningitis. J Virol 1997; 71: 78327840 .

[69] Glass WG, Chen BP, Liu MT, Lane TE. Mouse hepatitis virus infection of the central nervous system: chemokine mediated regulation of host defense and disease. Viral Immunol 2002; 15: 262272.

[70] Ireland DDC, Reiss CS. Gene expression contributing to recruitment of circulating cells in response to vesicular stomatitis virus infection of CNS. Viral Immunol 2006; 19: 535-545.

[71] Luster AD, Ravetch JV. Biochemical characterization of a gamma interferon-inducible cytokine (IP-10) J Exp Med 1987; 166: 1084 1097.

[72] Liu MT, Chen BP, Oertel P, et al. Cutting Edge: The T cell chemoattractant IFN-inducible protein 10 is essential in host defense against viral-induced neurologic disease. J Immunol 2000; 165: 2327-2730

[73] Khan I, MacLean JA, Lee F, et al. The IP-10 chemokine is critical for effector $\mathrm{T}$ cell trafficking and host survival in Toxoplasma gondii infection. Immunity 2000; 12: 483-494.

[74] Cheeran MC, Gekker G, Hu S, Min X, Cox D, Lokensgard JR. Intracerebral infection with murine cytomegalovirus induces CXCL10 and is restricted by adoptive transfer of splenocytes. J Neurovirol 2004; 10: 152-162.

[75] Hsieh M, Lai S, Chen J, et al. Both CXCR3 and CXCL10/IFNinducible protein 10 are required for resistance to primary infection by dengue virus. J Immunol 2006; 177: 1855-1863.

[76] Christensen JE, Lemos C, Moos T, Christensen JP, Thomsen AR. CXCL10 is the key ligand for CXCR3 on CD8+ T cells involved in immune surveillance of the lymphocytic choriomeningitis virusinfected central nervous system. J Immunol 2006; 176: 4235-4243.

[77] Sasseville VG, Smith MM, Mackay CR, et al. Chemokine expression in simian immunodeficiency virus-induced AIDS encephalitis. Am J Pathol 1996; 149: 1459-1467.

[78] Zou JY, Crews FT. TNF alpha potentiates glutamate neurotoxicity by inhibiting glutamate uptake in organotypic brain slice cultures: neuroprotection by NFkB inhibition. Brain Res 2005; 1034: 11-24.

[79] Mahad D, Callahan MK, Williams KA, et al. Modulating CCR2 and CCL2 at the blood-brain barrier: relevance for multiple sclerosis pathogenesis. Brain 2006; 129: 212-223.

[80] Maus UA, Wellman S, Hampl C, et al. CCR2-positive monocytes recruited to lungs downregulate local CCL2 chemokine levels. Am J Physiol Cell Mol Physiol 2005; 288: L350-L358.

[81] Eugenin EA, Osiecki K, Lopez L, Goldstein H, Calderon TM, Berman JW. CCL2/Monocyte chemoattractant protein-1 mediates enhanced transmigration of human immunodeficiency virus (HIV)infected leukocytes across the blood-brain barrier: a potential mechanism of HIV-CNS invasion and neuroAIDS. J Neuroscien 2006; 26 (4): 1098-1106.

[82] Rollins BJ. Monocyte chemoattractant protein 1: a potential regulator of monocyte recruitment in inflammatory disease. Mol Med Today 1996; 2: 198-204.

[83] Izikson L, Klein RS, Charo IF, Weiner HL, Luster AD. Resistance to experimental autoimmune encephalomyelitis in mice lacking the CC chemokine receptor (CCR) 2. J Exp Med 2000; 192: 10751080 
[84] Ueda A, Okuda K, Ohno S, et al. NF-kappaB and spl regulate transcription of the human monocyte chemoattractant protein-1 gene. J Immunol 1994; 153: 2052-2063.

[85] Martin T, Cardarelli PM, Parry GCN, Felts KA, Cobb RR. Cytokine induction of monocyte chemoattractant protein-1 gene expression in human endothelial cells depends on the cooperative action of NF-kB and AP-1. Eur J Immunol 1997; 27: 1091-1097.

[86] Lin S, Kok S, Shun C, et al. Tumor necrosis factor-2 stimulates the expression of $\mathrm{C}-\mathrm{C}$ chemokine ligand 2 gene in fibroblasts from the human nasal polyp through the pathways of mitogen-activated protein kinase. Am J Rhinol 2007; 21: 2958-2959.

[87] Campbell SJ, Perry VH, Pitossi FJ, et al. Central nervous system injury triggers hepatic $\mathrm{CC}$ and $\mathrm{CXC}$ chemokine expression that is associated with leukocyte mobilization and recruitment to both the central nervous system and the liver. Am J Pathol 2005; 166: 14871497.

[88] Chen Y, Chiang W, Lin S, Wu K, Tsai T, Hsieh B. Dual regulation of TNF-2- induced CCL2/monocyte chemoattractant protein-1 expression in vascular smooth muscle cells by NF-kB and AP-1: modulation by Type III phosphodiesterase inhibition. J Pharmacol Exp Ther 2004; 103: 62620.

[89] Davatelis G, Tekamp-Olsel P, Wolpe SD, et al. Cloning and characterization of a cDNA for murine macrophage inflammatory protein (MIP), a novel monokine with inflammatory and chemokine properties. J Exp Med 1988; 167: 1939.

[90] Lukacs NW, Chensue SW, Smith RE et al. Production of monocyte chemoattractant protein-1 and macrophage inflammatory protein$1 \alpha$ by inflammatory granuloma fibroblasts. Am J Pathol 1994; 144: 711.

[91] Choe W, Volsky DJ, Potash MJ. Activation of NF-kB by R5 and $\mathrm{X} 4$ human immunodeficiency virus type 1 induces macrophage inflammatory protein $1 \alpha$ and tumor necrosis factor $\alpha$ in macrophages. J Virol 2002; 76: 5274-5277.

[92] Ramo CDL, Canetti C, Souto JT et al. MIP-1 $\alpha$ [CCL3] acting on the CCR1 receptor mediates neutrophil migration in immune inflammation via sequential release of TNF-2- and LTB4. J Leukoc Biol 2005; 167-177.

[93] Ishida Y, Kimura A, Kondo $\mathrm{T}$ et al. Essential roles of the $\mathrm{CC}$ chemokine ligand 3-CC chemokine receptor 5 axis in bleomycininduced pulmonary fibrosis through regulation of macrophage and fibrocyte infiltration. Am J Pathol 2007; 170: 843-854.

[94] Taub DD, Turcovski-Corrales SM, Key ML. Chemokines and T lymphocyte activation: I. Beta chemokines costimulate human T lymphocyte activation in vitro. J Immunol 1996; 156: 2095-2103.

[95] Shao W, Li X, Li M, Shi L, Qin Y, Li K. Macrophage inflammatory protein-1 $\alpha$ expression plasmid enhances DNA vaccine-induced immune responses against HSV-2. Immunol Cell Biol 2005; 83: 626-631.

[96] Sanchez-Burgos G, Hernandez-Pando R, Campbell IL, RamosCastenada J, Ramos C. Cytokine production in brain of mice experimentally infected with dengue virus. Neuroreport 2004; 15 : 3742.

[97] Karpus WJ, Lukacs NW, McRae BL, Strieter RM, Kunkel SL, Miller SD. An important role for the chemokine macrophage inflammatory protein- $1 \alpha$ in the pathogenesis of the T cell-mediated autoimmune disease, experimental autoimmune encephalomyelitis. J Immunol 1995; 155: 15003-5010.

[98] Schall TJ, Bacon K, Toy KJ, Goeddel DV. Selective attraction of monocytes and $\mathrm{T}$ lymphocytes of the memory phenotype by cytokine RANTES. Nature 1990; 347: 669-671.

[99] Kuna P, Alam R, Ruta U, Gorski P. RANTES induces nasal mucosal inflammation rich in eosinophils, basophils, and lymphocytes in vivo. Am J Respir Crit Care Med 1998; 157: 873-879.

[100] Sin J, Kim JJ, Pachuk C, Satishchandran C, Weiner DB. DNA vaccines encoding interleukin-8 and RANTES enhance antigenspecific Th1-type $\mathrm{CD}^{+}$T-cell-mediated protective immunity against herpes simple virus type 2 in vivo. J Virol 2000; 74 (23): $11173-11180$.
[101] Genin P, Algarte M, Roof P, Lin R, Hiscott J. Regulation of RANTES chemokine gene expression requires cooperativity between NF-kB and IFN-regulatory factor transcription factors. J Immunol 2000; 164: 5352-5361.

[102] Kujime K, Hashimoto S, Gon Y, Shimizu K, Horie T. p38 mitogenactivated protein kinase and c-jun-NH2-terminal kinase regulate RANTES production by influenza virus-infected human bronchial epithelial cells. J Immunol 2000; 164: 3222-3228.

[103] Lin R, Heylbroeck C, Genin P, Pitha PM, Hiscott J. Essential role of interferon regulatory factor 3 in direct activation of RANTES chemokine transcription. Mol Cell Biol 1999; 19: 959-966.

[104] Melchjorsen J, Paludan SR. Induction of RANTES/CCL5 by herpes simplex virus is regulated by nuclear factor $\mathrm{kB}$ and interferon regulatory factor 3. J Gen Virol 2003; 84: 2491-2495.

[105] Nelson PJ, Kim HT, Manning WC, Goralski TJ, Krensky AM. Genomic organization and transcriptional regulation of the RANTES chemokine gene. J Immunol 1993; 151: 2601.

[106] Stellato C, Beck LA, Gorgone GA, et al. Expression of the chemokine RANTES by a human bronchial epithelial cell line: modulation by cytokines and glucocorticoids. J Immunol 1995; 155: 410 .

[107] Lane TE, Liu MT, Chen BP, et al. A central role for CD4+ T cells and RANTES in virus-induced central nervous system inflammation and demyelination. J Virol 2000; 74 (3): 1415-1424.

[108] Loetscher M, Berber B, Loetscher P, et al. Chemokine receptor specific for IP10 and MIG: structure, function and expression in activated T-lymhocytes. J Exp Med 1996; 184: 963-969.

[109] Weng Y, Siciliano SJ, Waldburger KE, et al. Binding and functional properties of recombinant and endogenous CXCR3 chemokine receptors. J Biol Chem 1998; 273: 18288-18291.

[110] Sorensen TL, Tani M, Jensen J, et al. Expression of specific chemokines and chemokine receptors in the central nervous system of multiple sclerosis patients. J Clin Invest 1999; 103: 807-815.

[111] Yoneyama H, Matsuno K, Toda E, et al. Plasmacytoid DCs help lymph node DCs to induce anti-HSV CTLs. J Exp Med 2005; 202: 425-435.

[112] Wickham S, Lu B, Ash J, Carr DJ. Chemokine receptor deficiency is associated with increased chemokine expression in the peripheral and central nervous systems and increased resistance to herpetic encephalitis. J Neuroimmunol 2005; 162: 51-59.

[113] Lundberg P, Openshaw H, Wang M, Yang H, Cantin E. Effects of CXCR3 signaling on development of fatal encephalitis and corneal and periocular skin disease in HSV-infected mice are mouse-strain dependent. Invest Opthalmol Vis Sci 2007; 48: 4162-4170.

[114] Sorensen LN, Paludan SR. Blocking CC chemokine receptor (CCR) 1 and CCR5 during herpes simplex virus type 2 infection in vivo impairs host defence and perturbs the cytokine response. Scand J Immunol 2004; 321-333.

[115] Nansen A, Christensen JP, Andreasen SO, Bartholdy C, Christensen JE, Thomsen AR. The role of CC chemokine receptor 5 in antiviral immunity. Blood 2002; 99: 1237-1245.

[116] Khan IA, Thomas SY, Moretto MM, et al. CCR5 is essential for NK cell trafficking and host survival following Toxoplasma gondii infection. PLoS Pathog 2006, 2: 0484- 0500.

[117] DeLemos C, Christensen JE, Nansen A, et al. Opposing effects of CXCR3 and CCR5 deficiency on CD8+ T cell-mediated inflammation in the central nervous system of virus-infected mice. J Immunol 2005; 175: 1767-1775.

[118] Murphy KM, Travers P, Walport M. Janeway's Immunobiology, seventh edition, Garland Science; 2007.

[119] Randolph GJ, Angeli V, Swartz MA. Dendritic-cell trafficking to lymph nodes through lymphatic vessels. Nat Rev 2005; 5: 617-624.

[120] Yoneyama H, Matsuno K, Zhang Y, et al. Evidence for recruitment of plasmacytoid dendritic cell precursors to inflamed lymph nodes through high endothelial venules. Int Immunol 2004; 16: 915-928.

[121] Zhao X, Deak E, Soderberg K, et al. vaginal submucosal dendritic cells, but not Langerhans cells, induce protective Th1 responses to herpes simplex virus- 2. J Exp Med 2003; 197: 153-162. 